\title{
Suppression of cucumber stachyose synthase gene (CsSTS) inhibits phloem loading and reduces low temperature stress tolerance
}

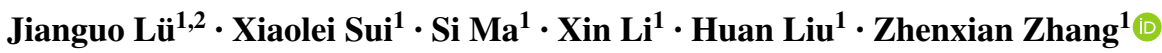

Received: 24 August 2016 / Accepted: 2 June 2017 / Published online: 12 June 2017

(c) The Author(s) 2017. This article is an open access publication

\begin{abstract}
Stachyose is the main transporting sugar in phloem of Raffinose family oligosaccharides-transporting species. Stachyose synthase (STS) is a key enzyme for stachyose biosynthesis, but the gene encoding STS is poorly characterized in cucumber (Cucumis sativus L.), which is a model plant for studying stachyose metabolism and phloem function. In this research, stachyose synthase gene (CSSTS) from cucumber was isolated and its physiological functions were analyzed. CSSTS expressed mainly in the phloem of the minor veins in mature leaves and localized to companion cells. Reverse genetics with CSSTS RNAi lines revealed obviously reductions in STS activity and stachyose content along with a small amount of starch accumulation in leaves, suggesting that CSSTS is involved in phloem loading of cucumber leaves. After $6^{\circ} \mathrm{C}$ low temperature stress, malondialdehyde content and electrical conductivity increased, especially in CSSTS-RNAi plants. But CsSTS expression was up-regulated, STS activity and stachyose level increased, the activities of reactive-oxygen-scavenging enzyme in cucumber seedlings improved significantly and starch accumulation reduced, especially
\end{abstract}

Jianguo Lü and Xiaolei Sui have contributed equally to this work.

Electronic supplementary material The online version of this article (doi:10.1007/s11103-017-0621-9) contains supplementary material, which is available to authorized users.

\section{Zhenxian Zhang}

zhangzx@cau.edu.cn

1 Beijing Key Laboratory of Growth and Developmental Regulation for Protected Vegetable Crops, College of Horticulture, China Agricultural University, Beijing 100193, China

2 College of Agricultural and Biological Sciences, Dali University, Dali 671003, Yunnan, China in CSSTS-OE lines. These results demonstrate clearly that CSSTS is involved in phloem loading, carbohydrate distribution and tolerance of cucumber seedlings to low temperature stress.

Keywords Cucumber - Low temperature stress - Phloem · Stachyose $\cdot$ Stachyose synthase

\section{Introduction}

The ability of plants to translocate a portion of photosynthetically derived carbon for storage allows them to grow and survive in a variety of environments and under many different conditions (Unda et al. 2012). Phloem loading is a process by which sugars and other products of photosynthesis are exported from mesophyll cells into the sieve elements (SE) and companion cells (CC) within minor veins of plants (Gamalei 2007; Turgeon and Wolf 2009). In most plants, sucrose serves as the primary transported sugar. In addition to sucrose, the Raffinose family oligosaccharides (RFOs) including stachyose and raffinose, are used in some plant species such as Cucurbitaceae and Scrophulariaceae for long-distance transport (Hendrix 1982; Mitchell and Mador 1992). In some other species, such as Rosaceae, sugar alcohol (sorbitol or mannitol) is the main component for phloem transport next to sucrose (Loescher and Everard 2000; Noiraud et al. 2001).

The three principal mechanisms of phloem loading include one apoplastic and two symplastic pathways (Rennie and Turgeon 2009; Slewinski and Braun 2010). The two symplastic loading pathways identified for sugar are the thermodynamically active and passive pathways (Reidel et al. 2009; Rennie and Turgeon 2009; Turgeon 2010). Hence, it is generally accepted that three strategies or types 
of phloem loading can be defined in the minor veins of plant: passive symplastic diffusion, active symplastic polymer trapping, and active apoplastic loading.

Passive symplastic loading (diffusion) mechanism in some species, such as a large number of woody species, especially trees, is driven by diffusion along a concentration gradient to enter phloem sieve tubes through the plasmodesmata from the high sucrose concentrations (in some cases sugar alcohols) in mesophyll cells, and requires no energy (Rennie and Turgeon 2009; Slewinski and Braun 2010). The active process of symplastic polymer trapping mechanism involves diffusion of assimilates synthesized in the mesophyll cells from the bundle sheath cells through abundant plasmodesmata into specialized companion cells (intermediary cells, i.e., IC), where the diffused assimilates are converted into the larger oligosaccharides (RFOs), raffinose and stachyose. A remarkable feature of this mechanism is the size exclusion limits of those plasmodesmata between the IC and the mesophyll cells allow diffusion of sucrose into the IC, but do not permit diffusion of the larger molecular weight sugars, RFOs, in the opposite direction. Polymer trapping is a thermodynamically active mechanism since energy is used to create a concentration difference between the mesophyll cells and the SE-CC complex (Turgeon 2010).

In active apoplastic loading pathway, sucrose synthesized in the mesophyll cells moves into phloem parenchyma cells by symplastic transfering and is then loaded into the phloem by specific transport proteins (Ayre 2011). Because sucrose is exported against the concentration gradient, this importation process requires energy (Giaquinta 1983). At present, the transport proteins known to be involved in carbohydrate phloem loading are mainly sucrose transporters (SUTs) (Riesmeier et al. 1994; Gottwald et al. 2000; Lalonde et al. 2004; Ayre 2011) and SWEETs, a novel class of sugar transporters (Chen et al. 2012). In the apoplastic phloem loading species Arabidopsis thaliana and Solanaceous species, SWEETs and SUTs participate in the process together, with SWEET transporters moving sucrose across phloem parenchyma cells to apoplast where sucrose is imported into sieve element by SUTs (Braun et al. 2013). In addition, in some plants, phloem loading may simultaneously occur through a variety of different pathways at the same time even within a single vein (Voitsekhovskaja et al. 2009; Slewinski et al. 2013). In certain cases such as biotic or abiotic stress, phloem loading mechanisms in some plants could be modulated (Gil et al. 2011; Lemoine et al. 2013).

RFOs are widespread in plant species, in addition to phloem transport, their physiological functions include carbon storage and protection against various stresses (Sengupta et al. 2015). In seeds, RFOs are prominent soluble sugars and serve as an essential source of easily accessible carbon during early germination (Downie and Bewley 2001). Stachyose and raffinose are the two important and major soluble sugars among RFOs; stachyose biosynthesis involves the following three steps (Fig. S1): galactinol synthase (GolS, EC 2.4.1.123) catalyses the first step in RFO biosynthesis by synthesizing galactinol from UDP-D-galactose and myo-inositol (Saravitz et al. 1987); raffinose is synthesized from sucrose and galactinol by raffinose synthase (RS, EC 2.4.1.82) and myo-inositol is produced as the leaving group; stachyose synthesis from raffinose and galactinol is catalyzed by stachyose synthase (STS, EC 2.4.1.67).

Stachyose synthase was originally described in seeds of bean (Tanner and Kandler 1968). Holthaus and Schmitz (1991a) purified STS from the leaves of melon; they also determined the optimal reaction temperature $\left(32^{\circ} \mathrm{C}\right), \mathrm{pH}$ (6.8) and $\mathrm{K}_{\mathrm{m}}$ (3.3 mM for raffinose and $7.7 \mathrm{mM}$ for galactinol) of STS. STS cDNA sequences were initially cloned from seeds of Adzuki Bean. Moreover, the expression of STS rapidly accumulates to high levels during seed development,and its activity is also detected upon seed germination (Peterbauer et al. 1999). The purification, characterization and heterologous expression of STS were reported from developing pea (Pisum sativum L.) seeds (Peterbauer et al. 2002).

Although cDNA sequences of STS have been cloned and characterized from several plants (Peterbauer et al. 1999, 2002; Voitsekhovskaja et al. 2009), the gene encoding STS in cucumber (Cucumis sativus L.), the classical stachyose-translocating plant (Pharr et al. 1985; Hu et al. 2009), has not been well studied. In this paper, we isolated a stachyose synthase gene (CsSTS) from cucumber. Using a combination of histochemical localization, reverse genetics, carbohydrate analysis and abiotic stress treatments, the function of CSSTS in symplastic phloem loading, photosynthate distribution and response to low temperature stress were characterized.

\section{Materials and methods}

\section{Plant materials and growth conditions}

Wild-type cucumber plants (C. sativus L. cv. Xintaimici) and transgenic cucumber lines (CsSTS-RNAi-1, 2, 3 lines and CsSTS-OE-1, 2, 3 lines) were used in this study. The plants were grown in greenhouse under normal management. For the carbohydrate analysis of transgenic plants, sampling time was at the end of night (around 4:15 am) and at the end of day (around 8:15 pm) respectively. For low temperature treatment, cucumber seedlings were incubated in a phytotron at $25 / 18^{\circ} \mathrm{C}$, in a $16 \mathrm{~h}$ day $/ 8 \mathrm{~h}$ night cycle. At the stage of four to five mature leaves, 
seedlings were exposed to $6{ }^{\circ} \mathrm{C}$ (day/night) and sampled at $0,12,24$ and $72 \mathrm{~h}$, respectively. The samples were quickly placed in liquid nitrogen and then stored at $-80^{\circ} \mathrm{C}$ for relative analysis.

\section{RNA extraction and quantitative RT-PCR analysis}

Total RNA samples were extracted using Column Plant RNA out kit (Tiandz, Beijing, China; http://www.tiandz. com), and cDNA was synthesized using PowerScript ${ }^{\mathrm{TM}}$ Reverse Transcriptase (Invitrogen, Carlsbad, CA, USA). The cDNA was then used as a template for quantitative real-time PCR (qRT-PCR) analysis, which was performed using SYBR ${ }^{\circledR}$ Premix Ex Taq ${ }^{\mathrm{TM}}$ from TaKaRa (China) on an Applied Biosystems 7500 RT-PCR system. The cucumber $\alpha$-TUBULIN (TUA) served as an internal control, and three biological replicates were performed.

\section{CsSTS gene cloning and phylogenetic analysis}

Based on the cucumber genomic sequence, a PCR fragment containing the complete CSSTS coding sequence was amplified from cDNA of mature leaves using specific primers (Table S1). The thermal cycling parameters were $95^{\circ} \mathrm{C}$ for $5 \mathrm{~min}, 35$ cycles of $95^{\circ} \mathrm{C}$ for $30 \mathrm{~s}, 55^{\circ} \mathrm{C}$ for $30 \mathrm{~s}$, and $72^{\circ} \mathrm{C}$ for $3 \mathrm{~min}$, and then $72^{\circ} \mathrm{C}$ for $10 \mathrm{~min}$. PCR products were cloned into pGEM-T Easy vectors (Promega, Madison, WI, USA) for gene sequencing.

The complete deduced amino acid sequences of related STS proteins in various species were obtained from the National Center for Biotechnology Information (the NCBI http://www.ncbi.nlm.nih.gov) (Fig. S2c). The phylogenetic tree was analyzed by using the neighbor-joining (NJ) method (Saitou and Nei 1987) with MEGA5 software (Tamura et al. 2011).

\section{Histochemical localization of GUS expression}

A pair of PCR primers (Table S1) was designed to amplify $1621 \mathrm{bp}$ of the CSSTS promoter. The PCR product was digested with HindIII and BamHI and was inserted 5' of GUS in vector pBI121, yielding construct $p C s S T S::$ GUS (Fig. S3a). Agrobacterium-mediated transformation was used to transfer the GUS reporter into cucumber. Histochemical localization of the GUS reporter in leaves was performed by incubating the tissues in GUS-staining solution at $37^{\circ} \mathrm{C}$ overnight. After staining, samples were cleaned with $75 \%$ ethanol and were observed under an anatomical lens. Some samples were prepared as paraffin sections for better observation.

\section{Immunolocalization}

For the immunohistochemical analyses, leaves from cucumber were fixed as described by Wang et al. (2014). After washing with phosphate buffered saline (PBS), the sections were blocked and initially incubated in a 1:200 dilution of rabbit anti-CsSTS antibody (CODE458; Beijing B\&M Biotech Co., Ltd), followed by an incubation with 1:200 dilution of secondary antibody (anti-rabbit IgG-alkaline phosphatase conjugate; Sigma). After several rinses with PBS, the sections were developed with substrate solution. After fixation, the slides were examined and photographed using microscopy.

\section{Subcellular localization in cucumber protoplasts and onion epidermal cells}

To study the subcellular localization of CsSTS protein, the open reading frame of CSSTS cDNA was amplified with gene-specific primers (Table S1) and inserted between the SmaI and BamHI sites of the pEZS-NL vector, and empty pEZS-NL vector was used as the control (Fig. S3b). The CsSTS::GFP fusion protein was transiently expressed in onion (Alliumcepa) epidermal cells, as described Hayes et al. (2007); the constructs were then introduced into cucumber protoplasts using Huang's method (2013). GFP fluorescence was visualized with a confocal laser-scanning microscope (Nikon C1, Japan).

\section{Vector construction and agrobacterium-mediated transformation}

To obtain the CSSTS over-expression lines, full-length cDNA of CSSTS was cloned and inserted the expression vector pBI121 between the SmaI and BamHI sites. To build the RNAi construct, two specific fragments of CSSTS were amplified using primers with incorporated $A s c \mathrm{I} / S w a \mathrm{I}$ sites and SpeI/BamHI sites, respectively. These fragments were then inserted into the pFGC1008 vector. Both over-expression and RNAi constructs were transformed into Agrobacterium tumefaciens strain LBA4404 respectively. The resulting vectors were transformed into cucumber using the fresh expanding cotyledon disk transformation method as previously described (Sui et al. 2012).

\section{Stachyose synthase (STS) activity assays}

STS was extracted and STS activities were performed according to Peterbauer and Richter (1998) with some modifications. Approximately $0.5 \mathrm{~g}$ fresh weight $(\mathrm{FW})$ of leaf samples were ground at $4{ }^{\circ} \mathrm{C}$ in $2 \mathrm{~mL}$ of chilled extraction buffer (50 mM HEPES-NaOH, pH 7.0; 2 mM DTT; $1 \%$ PVP). After 15 min' standing, the homogenate was 
centrifuged at $18,000 \times g$ for $30 \mathrm{~min}$. The supernatant was subject to dialysis at $4{ }^{\circ} \mathrm{C}$ for $16 \mathrm{~h}$ with buffer containing $25 \mathrm{mM}$ HEPES-NaOH (pH 7.0) and $1 \mathrm{mM}$ DTT, and then used to determine STS activity. The volume of $200 \mu \mathrm{L}$ reaction mixtures contained $100 \mathrm{mM}$ Hepes- $\mathrm{NaOH}(\mathrm{pH}$ 7.0), $20 \mathrm{mM} \beta$-mercaptoethanol, $40 \mathrm{mM}$ raffinose, $20 \mathrm{mM}$ galactinol, $5 \mathrm{mM} \mathrm{MgCl}{ }_{2}, 4 \mathrm{mM}$ DTT and $50 \mu \mathrm{L}$ enzyme solution. The mixtures were bathed in water at $30^{\circ} \mathrm{C}$ for $3 \mathrm{~h}$ and terminated by boiling for $5 \mathrm{~min}$. After cooling, the formation of stachyose was determined by high performance liquid chromatography (HPLC, Agilent 2100 system; Palo Alto, CA, USA) and STS activities were expressed by the content of stachyose. Protein concentration was determined by the method of Bradford with bovine serum albumin as the standard.

\section{Carbohydrate extraction and analysis}

Leaf samples (0.5 g FW) were extensively ground and extracted three times in $5 \mathrm{~mL} 80 \%(\mathrm{v} / \mathrm{v})$ ethanol for $30 \mathrm{~min}$ at $80^{\circ} \mathrm{C}$. The extracts were combined and decolorized with activated carbon, and then dried at $40^{\circ} \mathrm{C}$ in vacuum. The residues were re-dissolved in $1 \mathrm{~mL}$ distilled water and then passed through a $0.45 \mu \mathrm{m}$ filter. Carbohydrate content was determined by high performance liquid chromatography (HPLC, Agilent 2100 system; Palo Alto, CA, USA) using a Sugar-Park column (Waters, $6.5 \mathrm{~mm} \times 300 \mathrm{~mm}$ ). Samples were eluted with water at $75^{\circ} \mathrm{C}$ and a flow rate of $0.5 \mathrm{~mL} \mathrm{~min}^{-1}$; carbohydrates were detected with a refractive index detector. Eluted sugars were identified and quantified from the retention times and peak heights of sugar standards.

\section{Starch measurement and staining}

The fresh sample tissues of $100 \mathrm{mg}$ were taken from the same timeframe. Three biological replicates were done for each time point. A starch measurement kit (Megazyme total starch assay kit) was used to quantify starch content. According to the manufacturer's protocols of procedure,the starch content was determined by amyloglucosidase/ $\alpha$ amylase method. The leaves were collected after $18 \mathrm{~h}$ of dark treatment and decolorized in $80 \%$ ethanol at $70^{\circ} \mathrm{C}$. The tissues were immersed in $10 \%$ I-KI staining solution for $30 \mathrm{~min}$. After staining, they were washed twice with water for $5 \mathrm{~min}$ to remove excess stain. Stained leaves were imaged and photographed under an anatomical lens.

\section{Measurement of antioxidant enzyme activities}

The activity of superoxide dismutase (SOD) was determined by the method as described by Giannopolitis and Ries (1977), according to its ability to inhibit the photoreduction of nitroblue tetrazolium (NBT). The amount of enzyme required to inhibit 50\% of the NBT photoreduction was defined as 1 unit of enzyme activity. Catalase (CAT) activity and peroxidase (POD) activity were assayed according the method of Cakmak and Marschner (1992). For the CAT activities, the reaction mixture of $2 \mathrm{~mL}$ contained $1700 \mu \mathrm{L}$ of $25 \mathrm{mM}$ phosphate buffer (pH 7.0), $200 \mu \mathrm{L}$ of $10 \mathrm{mM} \mathrm{H} \mathrm{H}_{2} \mathrm{O}_{2}$ and enzyme extract. The decomposition of $\mathrm{H}_{2} \mathrm{O}_{2}$ was followed at $240 \mathrm{~nm}$ (coefficient of absorbance, $39.4 \mathrm{mM} \mathrm{cm} \mathrm{cm}^{-1}$ ). For the measurement of POD activities, the reaction mixture contained $100 \mu \mathrm{L}$ of supernatant, $25 \mathrm{mM}$ phosphate buffer ( $\mathrm{pH} 7.0$ ), $1 \%$ guaiacol, $20 \mathrm{mM} \mathrm{H}_{2} \mathrm{O}_{2}$, then reacted under $25^{\circ} \mathrm{C}$, the kinetic changes were determined at $470 \mathrm{~nm}$ by ultraviolet-uisible spectrophotometer (coefficient of absorbance, $26.6 \mathrm{mM} \mathrm{cm}^{-1}$ ).

\section{Determination of lipid peroxidation}

The level of lipid peroxidation in the leaves was estimated by measuring MDA content, following the method described by $\mathrm{Wu}$ et al. (2012). $0.5 \mathrm{~g}$ (FW) leaf material was homogenized in $10 \mathrm{~mL}$ of $10 \%(\mathrm{~m} / \mathrm{v})$ trichloroacetic acid (TCA), and then the homogenate was centrifuged at $4000 \mathrm{r} \mathrm{min}^{-1}$ for $10 \mathrm{~min}$. The supernatant obtained for $2 \mathrm{~mL}$ was added to $2 \mathrm{~mL}$ of $0.6 \%(\mathrm{~m} / \mathrm{v})$ thiobarbituric acid (TBA). The mixture was reacted in boiling water for $15 \mathrm{~min}$, and then was centrifuged again after cooling. The absorbance values of homogenate were measured at 450 , 532 and $600 \mathrm{~nm}$, respectively.

\section{The analysis of proline (Pro)}

According to Shan's way (2007), fresh leaf material came from different types was weighed about $0.5 \mathrm{~g}$, then extracted after adding $5 \mathrm{~mL}$ of $3 \%$ sulfosalicylic acid to them at $100^{\circ} \mathrm{C}$ for $10 \mathrm{~min}$, the extracts analyzed for proline content using the acid ninhydrin method. The extract for $2 \mathrm{~mL}$ was mixed with $2 \mathrm{~mL}$ of acid ninhydrin reagent and $2 \mathrm{~mL}$ of glacial acetic acid and heated at $100^{\circ} \mathrm{C}$ for $40 \mathrm{~min}$. After cooling, the mixture was reacted with $4 \mathrm{~mL}$ toluene and then the absorbance of the organic phase was determined at $520 \mathrm{~nm}$.

\section{Determination of relative electrical conductivity (REC)}

Follow the method described by Liu et al. (2013). The leaves were marinate at room temperature for $12 \mathrm{~h}$ and then the electrical conductivity (EC) of the exosmosed solution was measured (C1). The leaves were then boiled for $30 \mathrm{~min}$ and the EC was measured again (C2). REC was calculated as $(\mathrm{C} 1 / \mathrm{C} 2) \times 100 \%$. 


\section{Results}

\section{Isolation and sequence analysis of CsSTS}

The isolated full length cDNA of CSSTS (GenBank accession No. EF382356) is 2861 bp, and contains a $2595 \mathrm{bp}$ open reading frame encoding a predicted polypeptide of 864 amino acids. Sequence analysis of CSSTS cDNA revealed a 109 bp 5' untranslated region (UTR), a 157 bp 3' UTR, four exons and three introns (Fig. S2a). The sequence homology of CsSTS is $97.6 \%$ with STS of Cucumis melo; it has 71.3, 65.6, and 59.5\% sequence homology with those of Alonsoa meridionalis, P. sativum and A. thaliana, respectively (Fig. S2b). According to the Henrissat glycosyl hydrolase classification system (Henrissat and Davies 2000), all of these proteins belong to glycosyl hydrolase family 36 of the glycosidase super-family GH-D. This super-family is formed by $\alpha$-galactosidases from families 27 and 36 (Dagnall et al. 1995).
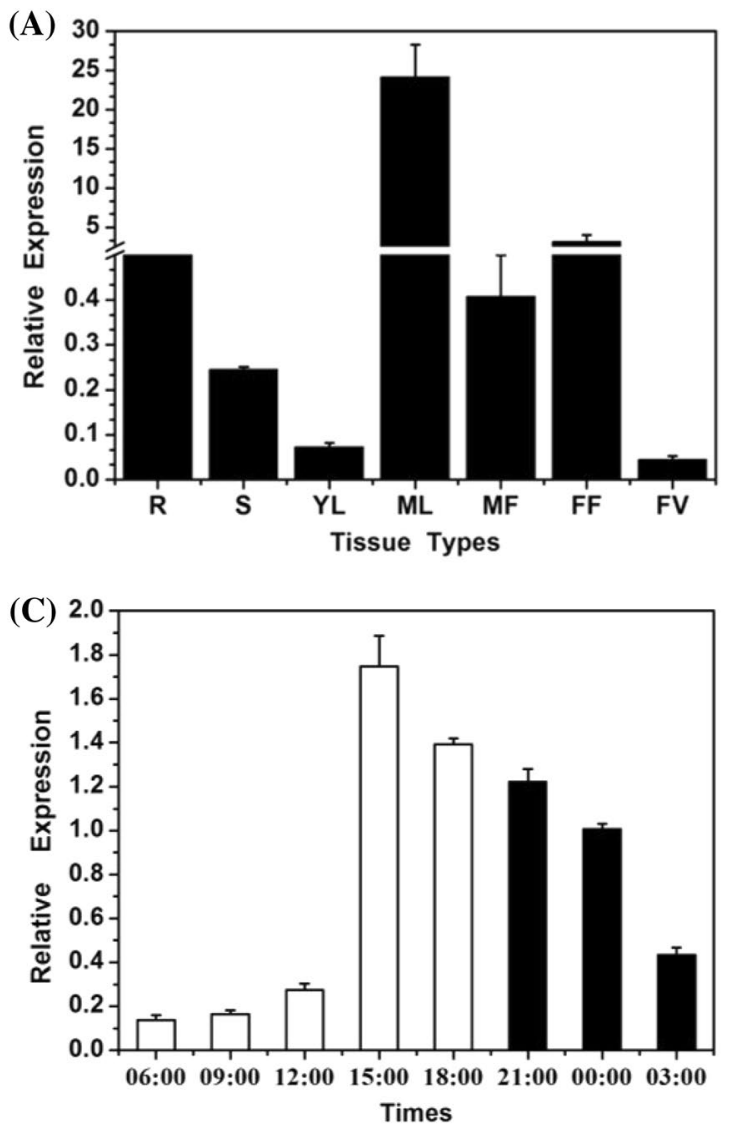

Fig. 1 Spatiotemporal expression of CsSTS. a CsSTS expression in different cucumber tissues. b CSSTS expression during leaf development. c Circadian variation of CSSTS expression in mature leaves. d The expression of $C S S T S$ in leaf veins. $R$ Root, $S$ Stem, $Y L$ Young leaf, $M L$ Mature leaf, $M F$ Male flower, $F F$ Female flower, $F V$ Fruit of
To further understand the evolutionary relationship between CSSTS and other STS homologues, phylogenetic analysis was performed. It revealed that the CSSTS (marked by a black triangle symbol) is highly homologous to STS from melon (CmSTS), but is clearly separated from zea mays stachyose synthase (ZmSTS) and medicago truncatula stachyose synthase (MtSTS) (Fig. S2c).

\section{The spatiotemporal expression of CsSTS}

Spatiotemporal expression analysis indicated that CSSTS expression occurred in all examined tissues; however, the transcript levels were the highest in mature leaves and were very low in other organs such as roots, stems, young leaves, male and female flowers and fruits (Fig. 1a). After leaf unfolding, relative expression levels of CSSTS increased gradually to a maximum on day 12 , and then declined rapidly (Fig. 1b). Over 24 h, CSSTS expression levels were lower in the morning and higher in the afternoon, peaking around 15:00 in the afternoon and then declining (Fig. 1c).

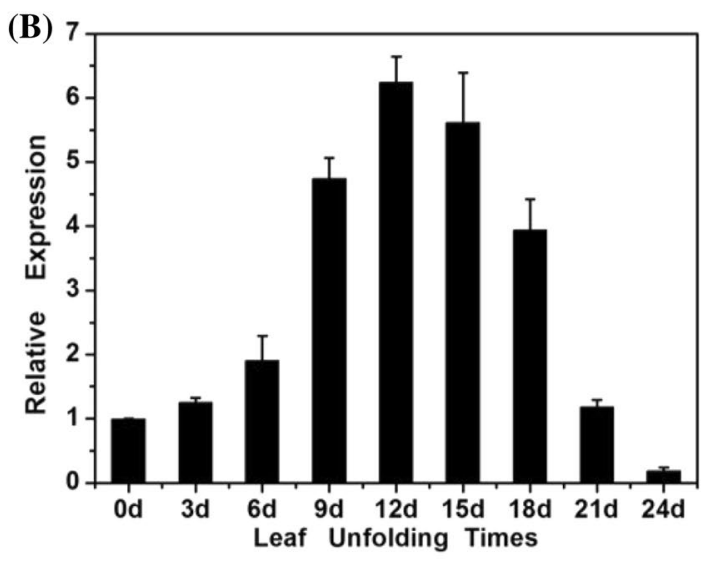

(D)

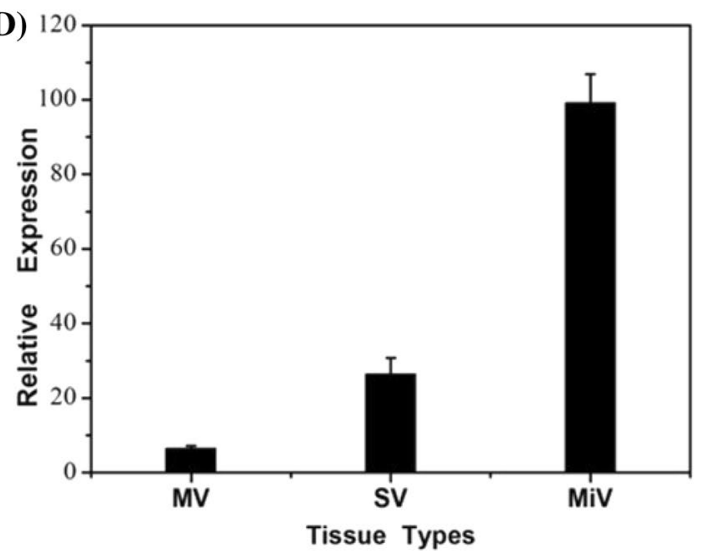

the 9th DAF (day after flowering), $d$ days, $M V$ main vein, $S V$ secondary vein, $M i V$ minor vein. The data were derived from three biological replicates, and TUA in cucumber was used as an internal control. Error bars represent standard deviations 
In addition, CSSTS was expressed mainly in minor vein phloem of leaves (Fig. 1d), revealing that CSSTS was not only responsible for stachyose synthesis, but may be also related to phloem loading in source leaves.

\section{The histochemical and subcellular localization of CsSTS}

Based on high CSSTS expression levels in leaves, we examined the detailed expression pattern of CSSTS in cucumber leaves by histochemical analysis of $p C S S T S:$ GUS plants (Fig. 2a, b, d, e, f) and immunolocalization (Fig. 2c, g, h, i). The results indicated that CSSTS was expressed mainly in minor veins (Fig. 2a-c). Further analysis demonstrated CSSTS expression in the bicollateral phloem of the vascular bundle in the minor veins of leaves, but not in vessel elements (Fig. 2e, h). The close-up of Fig. 2e, h clearly shows CSSTS targeting to companion cells (CC) (Fig. 2f, i). The subcellular localization of CSSTS was determined by expressing the CsSTS::GFP fusion protein in chloroplastfree epidermal cells of onion (Allium cepa) (Fig. 2j) and cucumber protoplasts (Fig. 2k), with empty GFP containing pEZS-NL serving as the control. The results showed that CSSTS::GFP was targeted to the plasma membrane, nucleus and cytosol of epidermal cells of onion, and the plasma membrane and cytosol of cucumber protoplasts.

\section{Construction of CsSTS -OE and CsSTS -RNAi lines}

In order to further confirm the biological function of CSSTS, the entire CsSTS coding sequence was amplified by PCR and inserted into the pBI121 plant expression vector in the sense orientation (Fig. 3a). At the same time, a double-strand RNAi vector was constructed containing the CSSTS specific sequence of under control of the $35 \mathrm{~S}$ promoter (Fig. 3b). Then, the constructs were introduced by Agrobacterium-mediated transformation into cucumber cotyledons for expression, and 20 transgenic plants were obtained. The expression level of CsSTS increased in OE lines and decreased in RNAi lines, suggesting that the CSSTS sequences were integrated into cucumber genome and functional (Fig. 3c). Based on CsSTS expression levels by qRT-PCR, three CsSTS-RNAi (RNAi-1, -2, -3) lines and three CSSTS-OE (OE-1, -2, -3) lines were selected for further study (Fig. 3c).

\section{Carbohydrate analysis of transgenic plants}

Compared with wild-type plants, both CSSTS-OE and CsSTS-RNAi transgenic lines seemed to have normal phenotypes; however, STS activities and stachyose contents in leaves of both transgenic lines and wild-type plants had marked differences (Fig. 4). Analysis of leaf STS activities showed that when compared to wild type, the STS activities were lower in CsSTS-RNAi lines and were higher in CSSTS-OE lines, especially at the end of night (Fig. 4a, c). The stachyose contents were lower in CSSTS-RNAi lines and higher in CSSTS-OE lines relative to wild-type, especially at the end of day (Fig. 4b, d).

Due to inhibition of stachyose synthesis and export in CsSTS-RNAi lines, there theoretically should be some starch accumulation. To this end, leaves detached from wild type and transgenic plants were placed in the dark for $18 \mathrm{~h}$, and then stained by iodine solution. The results revealed only trace amounts of accumulated starch in the CsSTS-OE and wild type lines, but there was still a small amount of starch in the leaves of the CsSTS-RNAi lines, suggesting that starch reserves in the CsSTS-RNAi lines remained even after $18 \mathrm{~h}$ of darkness (Fig. 4e). The above results demonstrated the promotion of stachyose synthesis and transport in CSSTS-OE lines, preventing starch accumulation. Conversely, stachyose synthesis and export were inhibited in CsSTS-RNAi lines, which accumulated a small amount of starch. These revealed that CSSTS plays a key role in phloem loading and transport of carbohydrate in cucumber leaves.

The sucrose transporters (SUTs) play an essential role in apoplastic phloem loading of sucrose (Riesmeier et al. 1994; Gottwald et al. 2000; Lalonde et al. 2004). There were three sucrose transmembrane transporters in cucumber named CSSUT1, CSSUT2 and CSSUT4, respectively. It is unknown whether cucumber SUT participates in phloem loading of cucumber which is generally classified as symplastic loaders. Interestingly, we found obvious differences in expression levels of the three cucumber sucrose transporters (CsSUTs) in transgenic lines and wild type plants. Compared with wild type, the expression level of SUT 1, 2 and 4 were significantly higher in CSSTS-RNAi lines; but in CSSTS-OE lines, their expression levels were similar to those of wild type lines (Fig. 5a). Accordingly, sucrose levels in the leaves of CSSTS-RNAi lines were reduced to a certain extent (Fig. 5b), and sucrose content (Fig. 5d) and distribution percentage (Fig. 5e) in the petiole increased slightly. Presumably, after suppression of stachyose synthesis, loading and export in CSSTS-RNAi lines, expression of SUTS were up-regulated to compensate via apoplastic phloem loading through SUT transmembrane transportation. In addition, compared with wild-type plants, raffinose content and distribution percentage obviously decreased in leaf blades (Fig. 5b, c), but significantly increased in petioles (Fig. 5d, e). It's likely that more amount of raffinose was loaded and transported to the petiole in CSSTS-RNAi plants. 

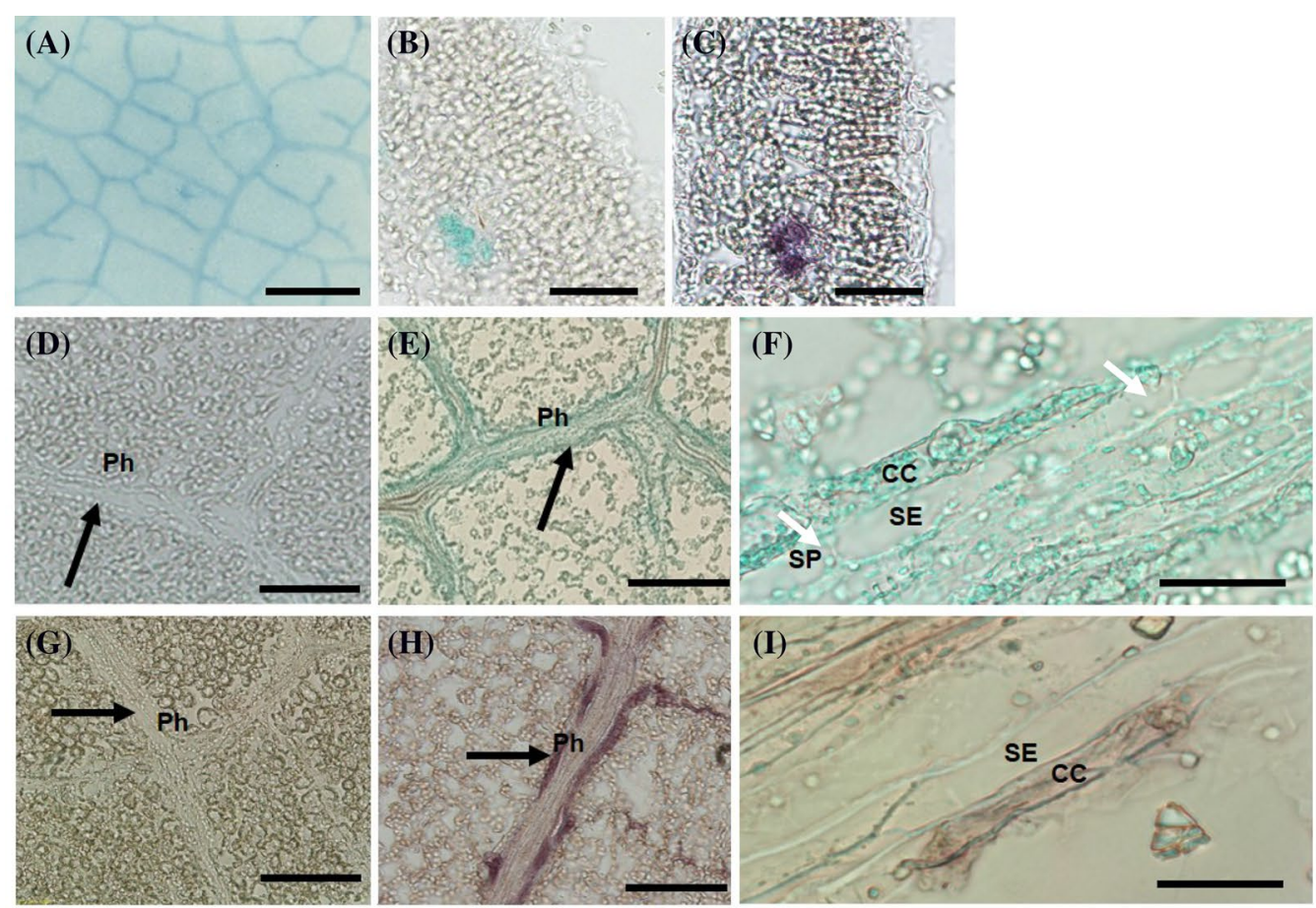

(J)

GFP

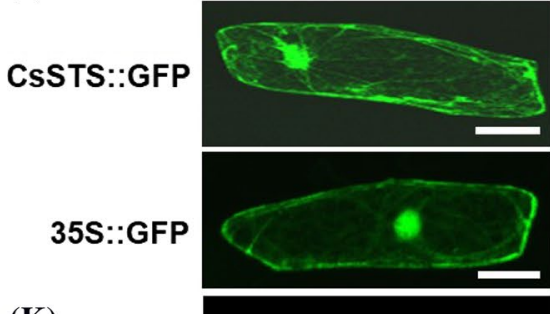

(K)
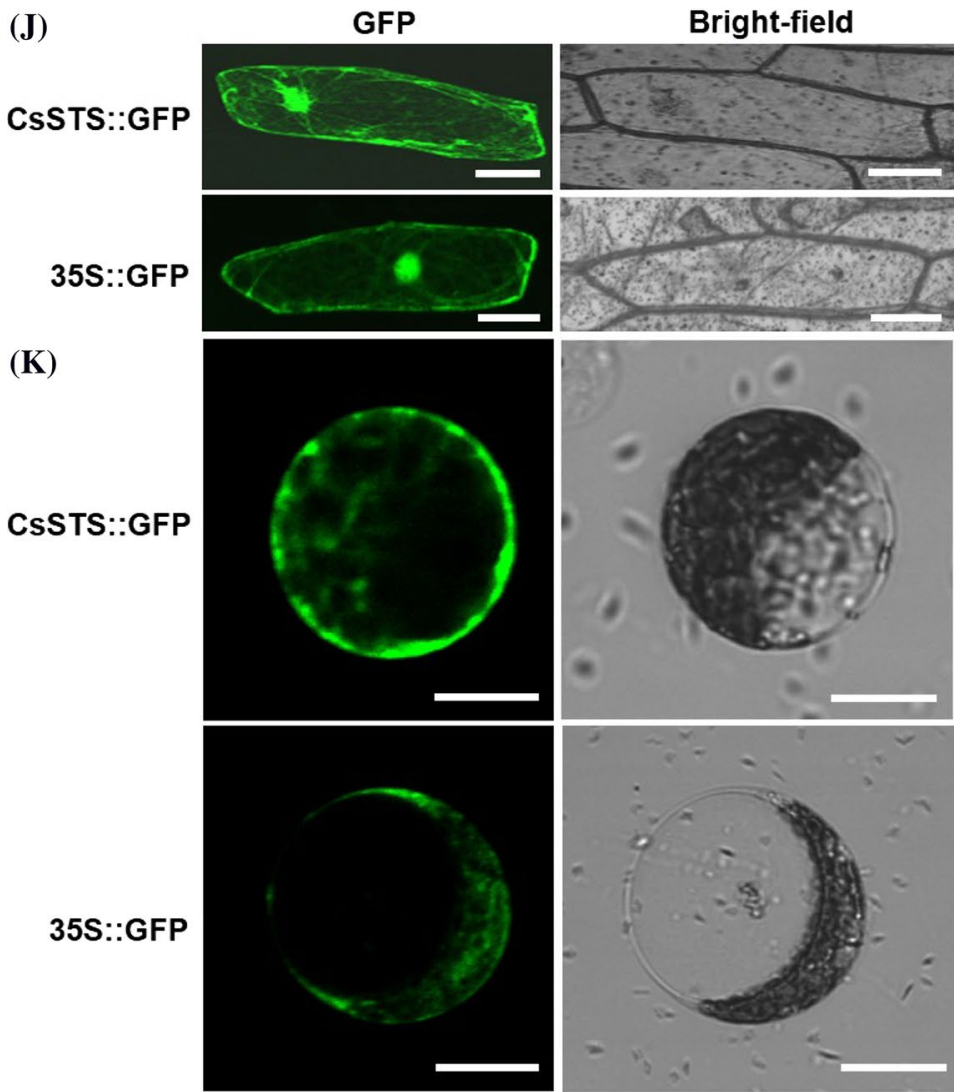

Merge
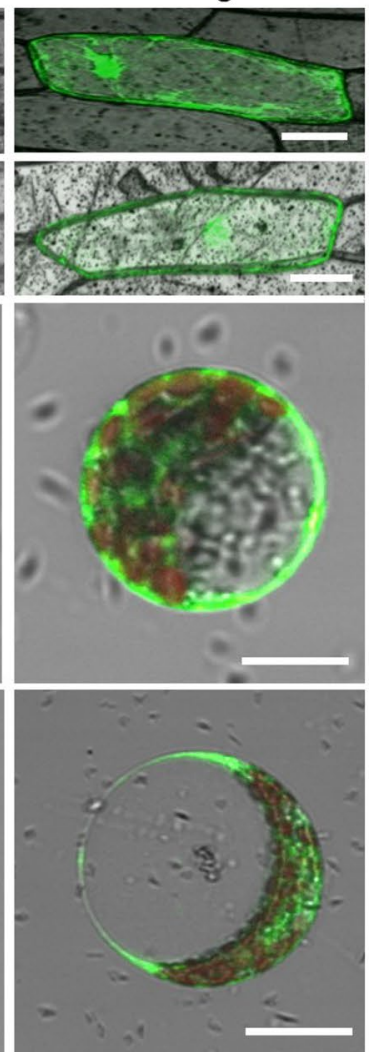

Fig. 2 Histochemical and subcellular localization of CsSTS. Histochemical analysis of $p C s S T S:$ GUS plants $(\mathbf{a}, \mathbf{b}, \mathbf{d}, \mathbf{e}, \mathbf{f})$; immunolocalization of CSSTS in cucumber leaves $(\mathbf{c}, \mathbf{g}, \mathbf{h}, \mathbf{i})$. The section of the leaf without GUS expression (d); The control sections treated with pre-immune serum $(\mathbf{g})$. Longitudinal sections $(\mathbf{d}-\mathbf{i})$; transverse sections $(\mathbf{b}, \mathbf{c})$. Black arrows indicate the $\mathrm{Ph}$ in $(\mathbf{d}, \mathbf{e}, \mathbf{g , h})$; white arrows in $\mathbf{f}$ indicate the SP. Subcellular localization of CsSTS protein in onion epidermal cells (j); Subcellular localization of CsSTS::GFP fusion protein in cucumber mesophyll protoplasts (k). CC companion cells, $S P$ sieve plate, $S E$ sieve element, $P h$ phloem. Scale bars denote: a $2 \mathrm{~mm}, \mathbf{b}$ and $\mathbf{c} 100 \mu \mathrm{m} ; \mathbf{d}, \mathbf{e}, \mathbf{g}, \mathbf{h} 200 \mu \mathrm{m} ; \mathbf{f}, \mathbf{i}, \mathbf{j} 50 \mu \mathrm{m} ; \mathbf{k} 20 \mu \mathrm{m}$ 
Fig. 3 Construction of CsSTSOE and CSSTS-RNAi lines. a Schematic diagram of STS gene over expression vector. b Diagram of the CSSTS-RNAi construct. c The relative expression analyses of CSSTS in WT, CSSTS-OE and CSSTS-RNAi lines by qRT-PCR. TUA in cucumber was used as an internal control, and the experiments were repeated in three intervals. $W T$ wild-type, $O E$ over expression lines; RNAi RNAi lines. Error bars indicate standard deviations
(A)

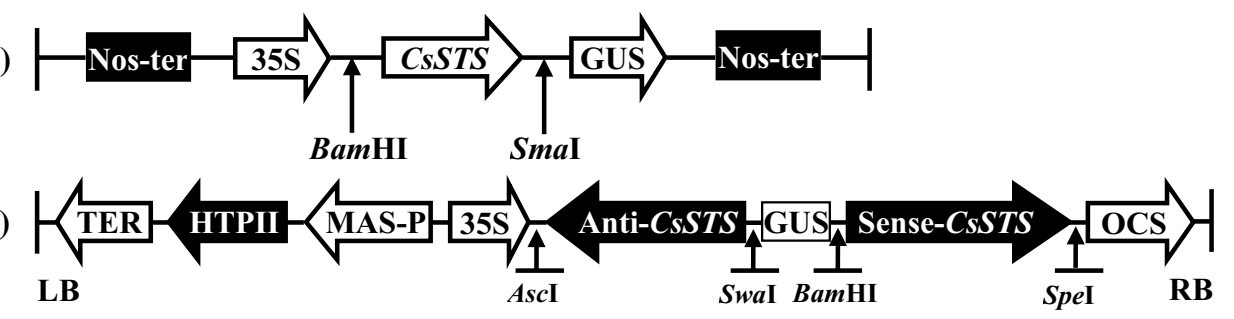

(C)

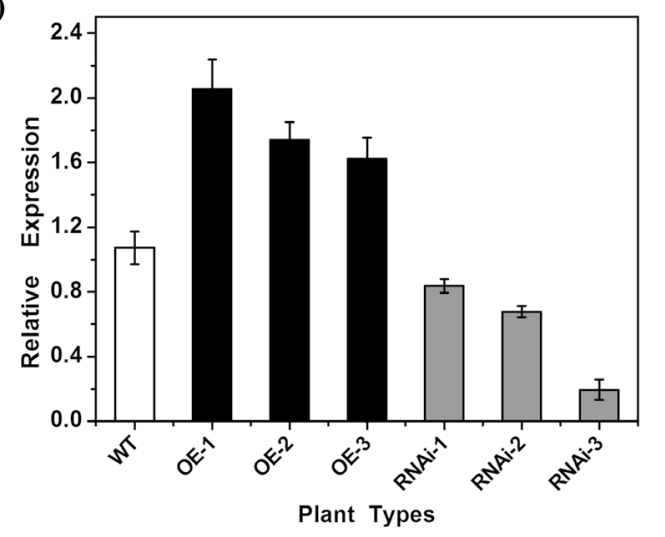

\section{CsSTS involved in response to low temperature stress}

Cucumber is a thermophilic crop, and easily suffers damage from low temperature stress. It is unknown whether cucumber stachyose synthase is involved in the response to low temperature stress. To this end, the seedlings mutant at the stage of four to five mature leaves were selected and treated with $6{ }^{\circ} \mathrm{C}$ (day/night) low temperature stress in order to further study the function of CsSTS (Figs. 6, 7). When suffered low temperature stress, CSSTS expression was up-regulated (Fig. 6a) and enzyme activities (Fig. 6b) and stachyose contents (Fig. 6c) increased gradually in wild type plants and transgenic plants after $24 \mathrm{~h}$, and declined after $72 \mathrm{~h}$ treatment. The leaves of CSSTS-RNAi lines experienced obvious wilting and sagging, whereas wild-type plants also had slight wilting symptoms, but the CSSTS-OE lines seemed to be normal in phenotype after $72 \mathrm{~h}$ low temperature treatment (Fig. 6e, f). During cold treatment, CsSTS expression, STS activities, and stachyose contents were always higher in CSSTS-OE lines and lower in CsSTS-RNAi lines relative to wild type plants (Fig. 6a-c). Stachyose content was significantly higher in CsSTS-OE lines than that in CSSTS-RNAi lines and wild type plants (Fig. 6c), suggesting that higher stachyose content contributed to enhanced low temperature stress tolerance. Moreover, a large amount of starch was accumulated in the leaves of CSSTS-RNAi lines during the stress treatment (Fig. 6d), which may reflect changes in RFO metabolic balance. By comparison, the CSSTS-OE lines and wild type had higher stachyose levels (Fig. 6c) and reduced accumulation of starch (Fig. 6d). These results suggest that stachyose plays an important role in cold tolerance of cucumber plants.

Physiologically, malondialdehyde (MDA) contents (Fig. 7a) and the relative electric conductivities (Fig. 7b) in the wild type and the mutant seedlings showed increase trend, especially in the CsSTS-RNAi lines during low temperature stress, which revealed that the cell membrane was probably damaged by reactive oxygen species (ROS) under low temperature stress. Accordingly, the activities of the reactive-oxygen-scavenging enzyme, such as superoxide dismutase (SOD) (Fig. 7c), catalase (CAT) (Fig. 7d) and peroxidase (POD) (Fig. 7e) in cucumber seedlings, increased gradually during low temperature stress, especially in CSSTS-OE lines. Moreover, the proline as an important osmotic regulation substance, its contents in the leaves of CSSTS-RNAi plants was lower than in the leaves of CsSTS-OE plants (Fig. 7f). These results showed that the reactive-oxygen-scavenging enzyme systems and the proline in cucumber seedlings play an important role to reduce low temperature stress damage.

\section{Discussion}

Raffinose family oligosaccharides (RFOs) metabolism is a complex process in plants which involves many enzymes. Among them, STS is one of the most important enzymes in the RFO biosynthetic pathway (Fig. S1), and stachyose and raffinose are the two main members of RFOs. Cucumber (C. sativus L.) is a stachyose-translocating plant (Pharr 
Night (8 h)

Day (16 h)

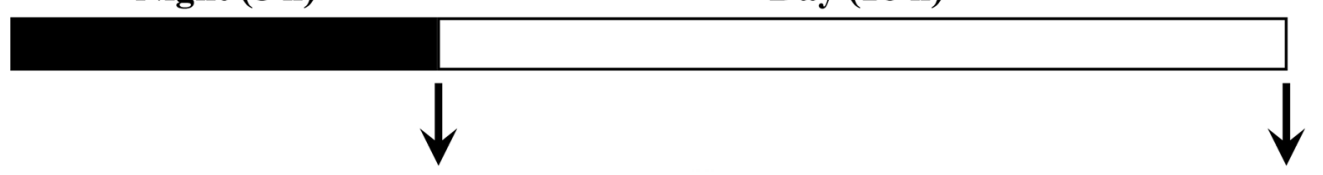

(A)

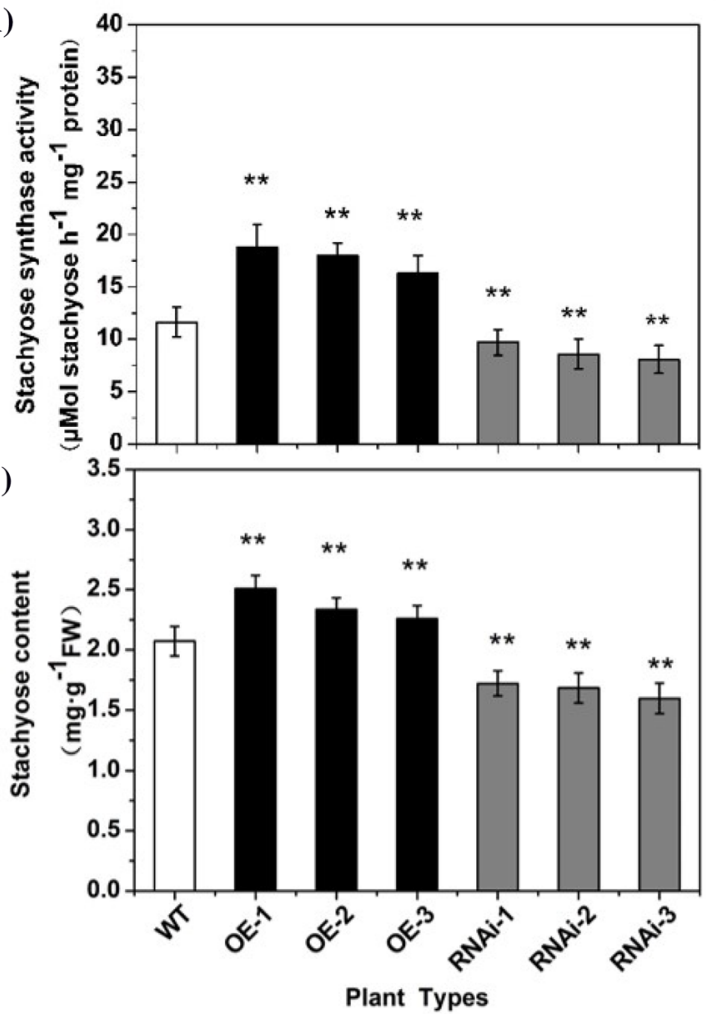

(C)

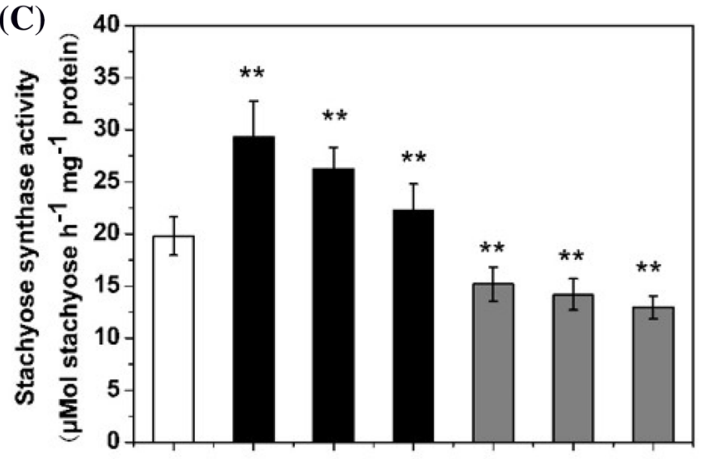

(D)

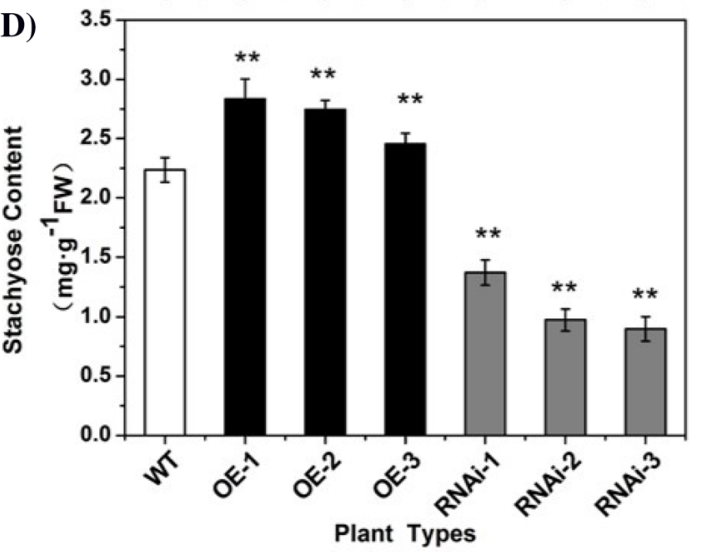

(E)

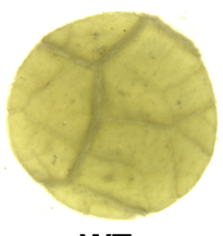

WT

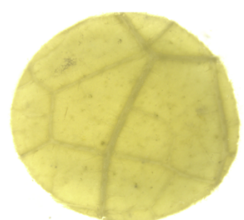

OE-1

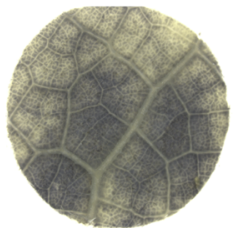

RNAi-1

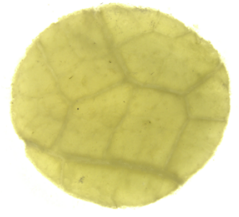

OE-2

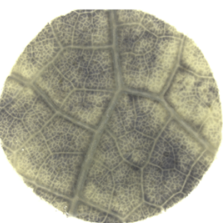

RNAi-2
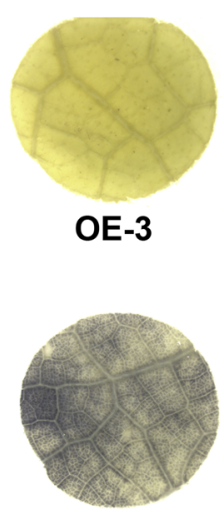

RNAi-3
Fig. 4 The STS activities, stachyose contents, starch staining of leaves in transgenic and wild-type cucumber. The STS activities (a, c) and stachyose contents $(\mathbf{b}, \mathbf{d})$ at the end of night $(\mathbf{a}, \mathbf{b})$ and at the end of day (c, d) respectively. The sampling time was around 4:15 am $(\mathbf{a}, \mathbf{b})$ and 8:15 pm $(\mathbf{c}, \mathbf{d})$, respectively. Staining of starch was done in

et al. 1985; Hu et al. 2009). Compared with the most sucrose-transporting plants, the source to sink carbohydrate metabolism of stachyose-transporting plants is more wild type and transgenic plants after $18 \mathrm{~h}$ of dark treatment (e). WT wild-type, $O E$ over expression lines, $R N A i$ RNAi lines. Each value is the mean \pm standard deviation of three replicates. Significance differences were determined by Duncan's test $(* P<0.05$, $* * P<0.01)$

complex. In early report, expression of STS in Cucurbitaceae was detected mainly in leaves and seeds (Hendrix 1968). In Scrophulariaceae, expression levels of STS were 
(A)

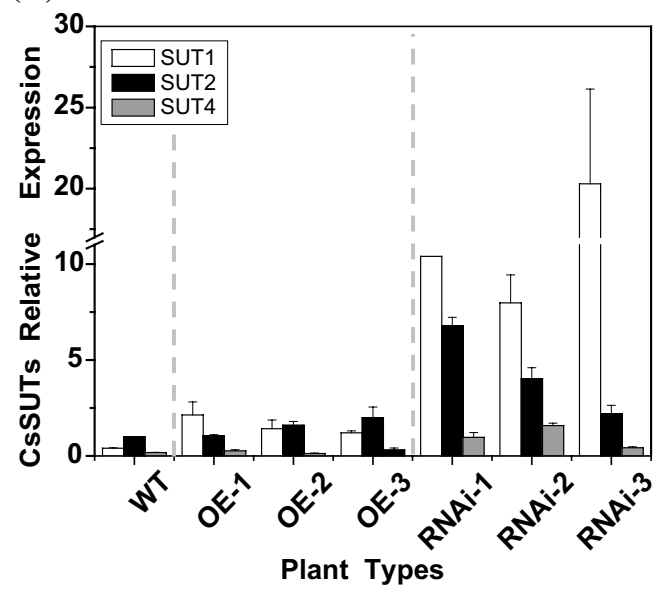

(B)
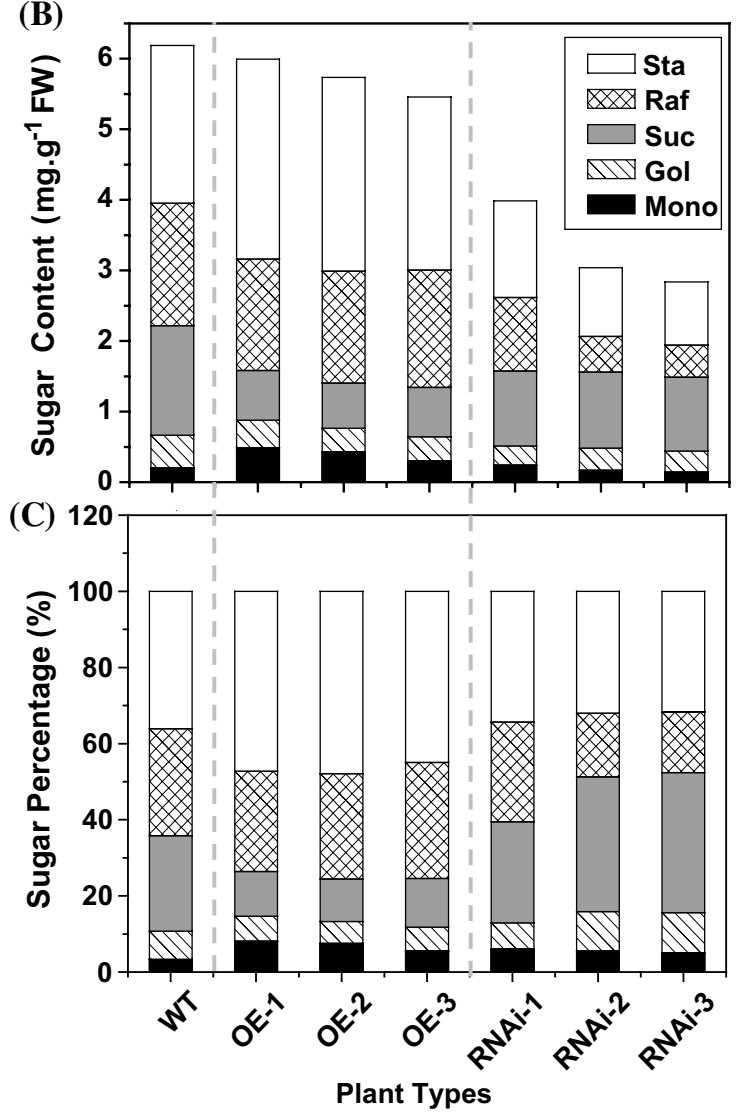

Fig. 5 The expression of sucrose transporters in leaves (a) and sugar contents and percentages in leaves $(\mathbf{b}, \mathbf{c})$ and petioles $(\mathbf{d}, \mathbf{e})$ of transgenic and wild-type cucumber plants. WT wild-type, $O E$ over expression plants, RNAi RNA interference lines, Sta stachyose, Raf raffi-

the highest in mature leaves and cotyledons, followed by young leaves; no hybridization signal was detected for RNA from stems, roots, flowers and fruits (Voitsekhovskaja et al. 2009). Similarly, in cucumber plants, the relative expression of STS was highest in mature leaves, especially in the minor veins (Fig. 1a, d).

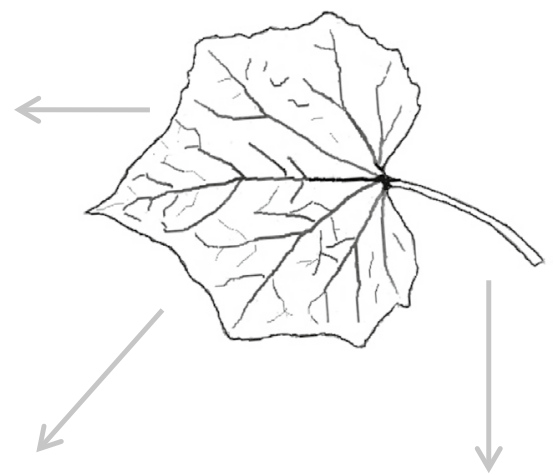

(D)
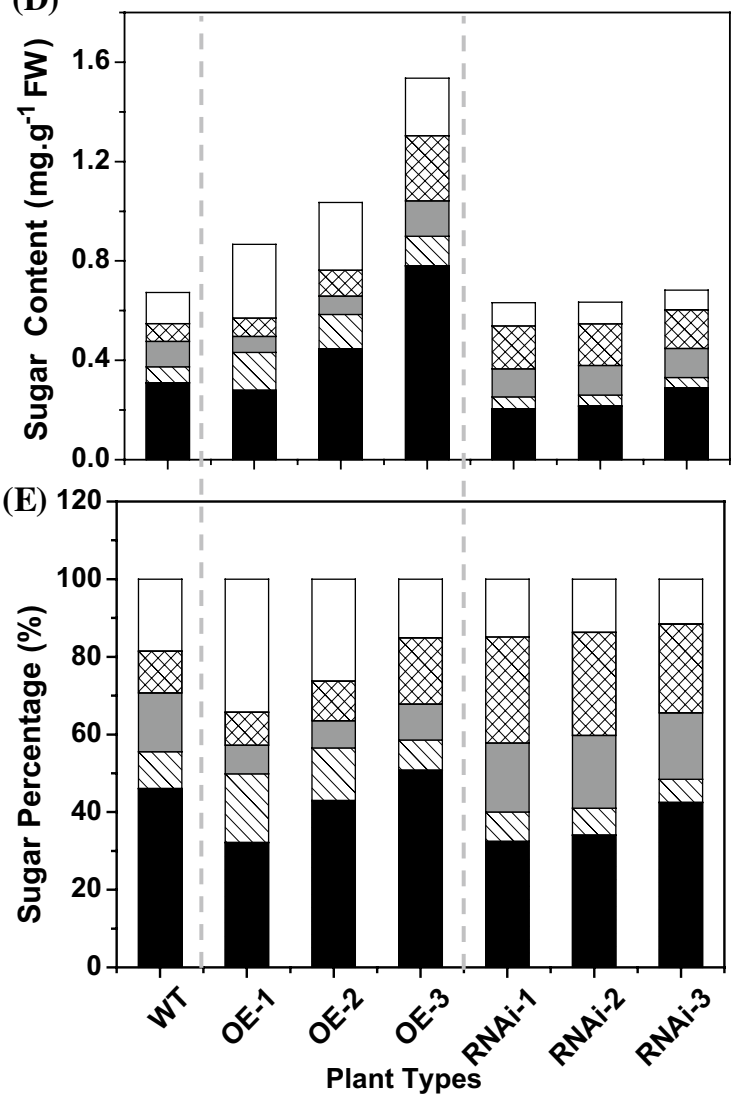

nose, Suc sucrose, Gol galactinol, Mono monosaccharide. TUA was used as an internal control and the experiments were repeated in three intervals. Error bars indicate the standard deviations

A more comprehensive localization of stachyose synthase was carried out by Holthaus and Schmitz (1991b). According to the indirect evidence of the distribution of stachyose, raffinose, galactinol and enzyme activities of STS, it was thought that stachyose was synthesized mainly in minor veins of mature leaves and in seeds. Furthormore, 
(A)

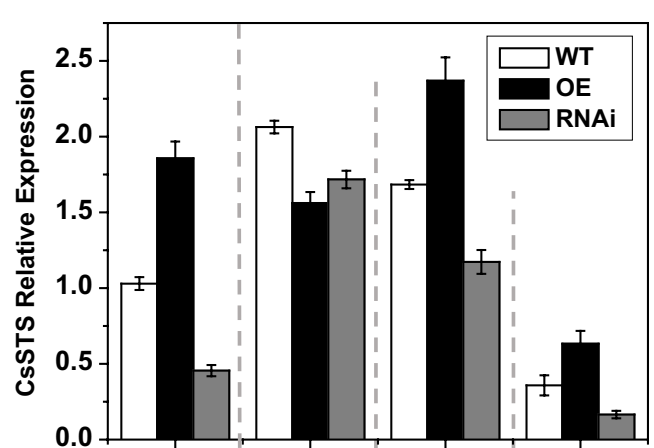

(C)

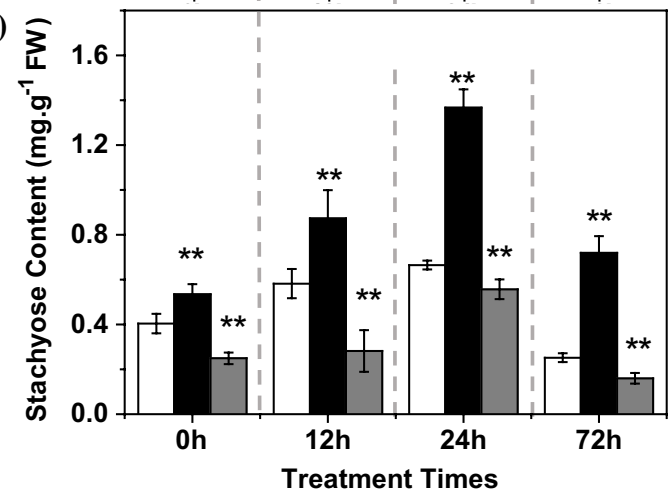

(E) Low temperature stress for $0 \mathrm{~h}$

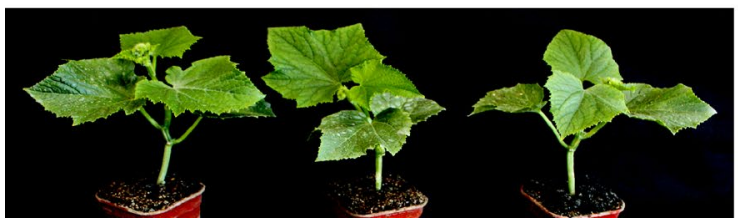

OE

RNAi

WT

Fig. 6 The effect of low temperature $\left(6^{\circ} \mathrm{C}\right)$ on gene expressions, activities of STS, stachyose contents, starch contents and phenotypes of leaf in transgenic and wild-type cucumber seedlings. a The CsSTS expression in leaves. b The activities of STS. c Stachyose contents. d Starch contents. The phenotypes of different plant types at $0 \mathrm{~h}(\mathbf{e})$

stachyose synthase had been detected in intermediary cells (IC) of minor vein phloem of Cucumis melo (Holthaus and Schmitz 1991b) and A. meridionalis (Voitsekhovskaja et al. 2009). Generally, there are three types of companion cells (CC) in stachyose-transporting species: intermediary cells (IC), transfer cells (TC) and ordinary companion cells (OCC). The main difference between IC cells and the other two types of companion cells is the presence of many plasmodesmata (Turgeon et al. 1975; Volk et al. 1996). According to the polymer trap mechanism (Turgeon 1996), a number of symplastic phloem loading species synthesize RFOs in the ICs of minor-vein phloem (Holthaus and Schmitz 1991b; Haritatos et al. 1996; Büchi et al. 1998; Voitsekhovskaja et al. 2009). In our histochemical analysis of $p C s S T S:$ GUS and immunolocalization of CsSTS in cucumber leaves (Fig. 2), CsSTS was targeted to

\section{(B)}

(D)

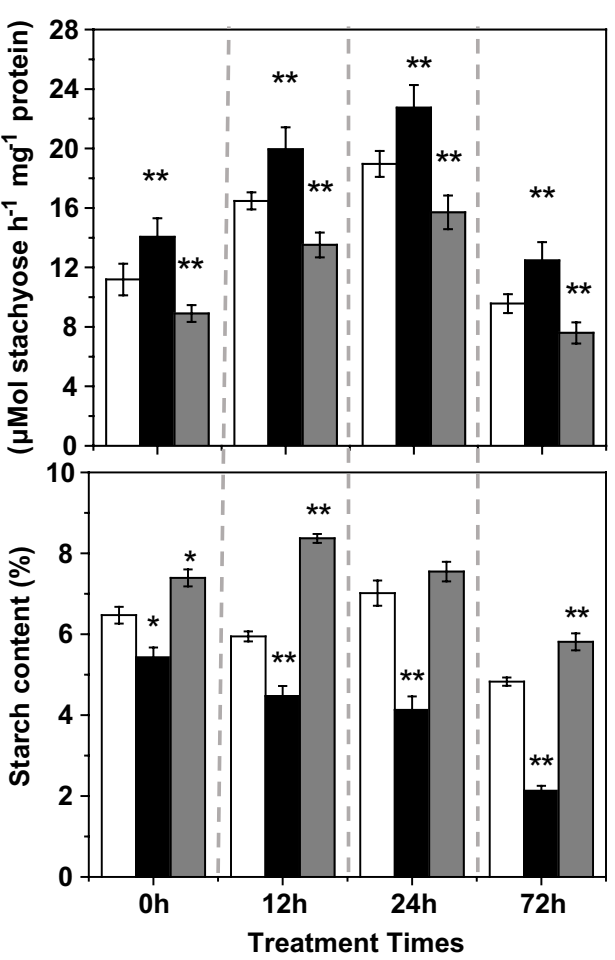

(F) Low temperature stress for $72 \mathrm{~h}$

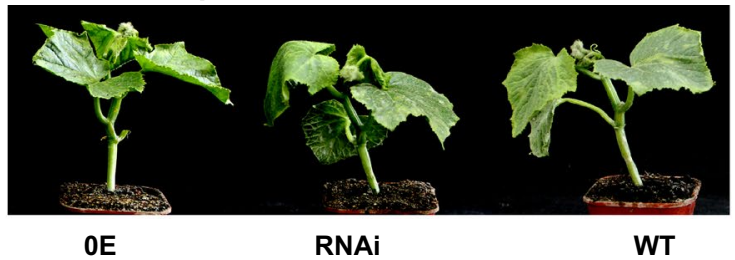

and $72 \mathrm{~h}(\mathbf{f})$ after low temperature treatment. $W T$ wild-type, $O E$ over expression lines, RNA $i$ RNA interference lines, $h$ hours. TUA was used as an internal control. Each value is the mean \pm standard deviation of three replicates. Significance differences were determined by Duncan's test $(* P<0.05, * * P<0.01)$

the companion cells (CC) of the minor-vein phloem. Data in this paper support the model that STS is targeted to IC, and is involved in symplastic phloem loading. The data provide further structural and anatomical details in cucumber, a typical Cucurbitaceae plant, refining the polymer trap model theory. Furthermore, based on localization results of CSSTS::GFP fusion protein in cucumber mesophyll protoplasts and onion epidermal cells, it is revealed that CSSTS is targeted to plasma membrane and cytosol (Fig. 2). In comparing with previous results, the localization results from our experiment were clearer in anatomy, more intuitive and accurate in ultrastructure and subcellular level.

Sucrose and starch are the primary products of photosynthesis in the leaves of most plants (Kötting et al. 2010). When phloem loading is inhibited in the symplastic or apoplastic pathways, starch will accumulate in leaves. Similar 
(A)

(C)
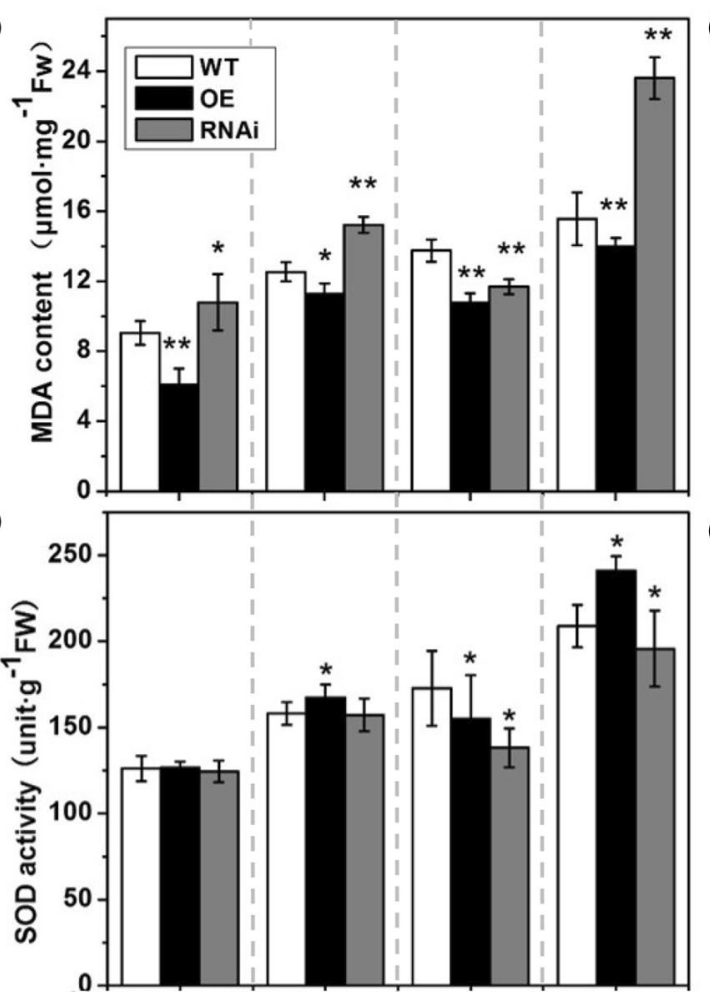

(E)

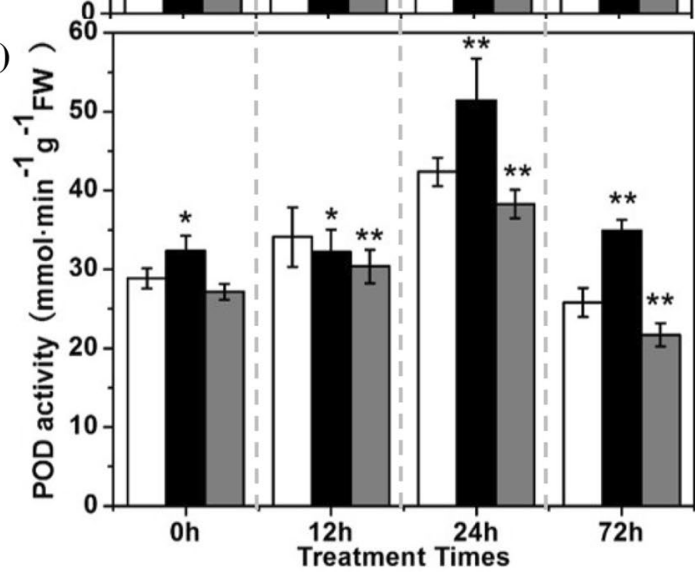

(B)

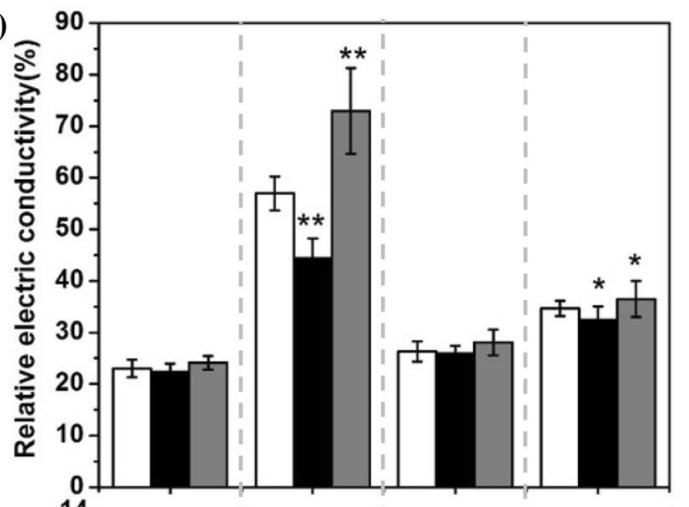

(D)

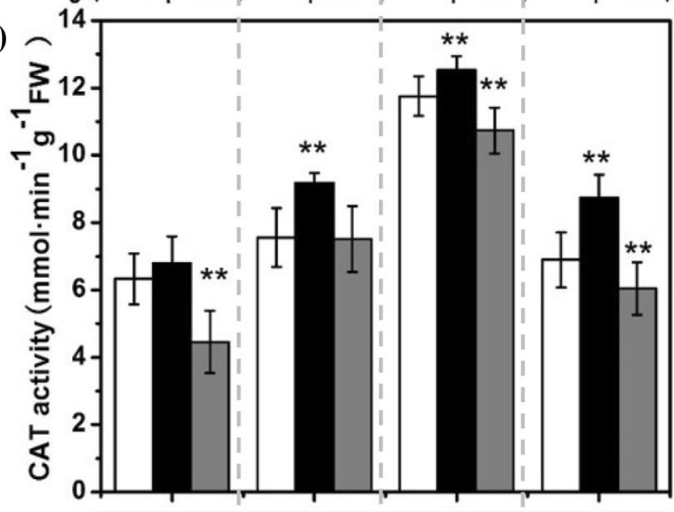

(F)

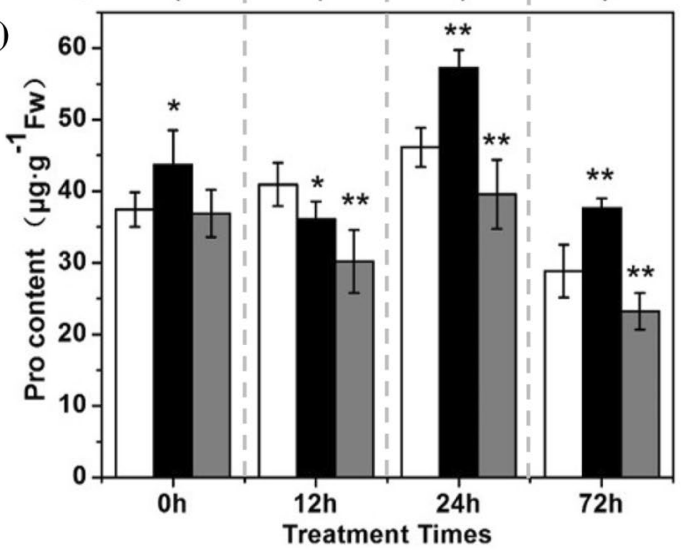

Fig. 7 The effects of low temperature $\left(6^{\circ} \mathrm{C}\right)$ on membrane peroxidation, activities of antioxidant enzymes and osmotic substance between the different plant types of cucumber seedlings. a Malondialdehyde (MDA) contents. b Relative electric conductivities. c Superoxide dismutase (SOD) activities. $\mathbf{d}$ Catalase (CAT) activities. e Per-

results were obtained in this paper when expression of CsSTS was altered compared with wild type lines, CsSTSRNAi lines accumulated starch in leaves and CsSTS-OE has significant reductions in stored starch (Fig. 4e), suggesting that phloem loading in CSSTS-RNAi lines was inhibited to some extent. At the same time, STS activities and stachyose contents were higher in the CsSTS-OE plants and lower in CSSTS-RNAi lines relative to wild type, especially at the end of night. These results revealed that export of photosynthate was suppressed to some extent in oxidase (POD) activities. f Proline contents. $W T$ wild-type, $O E$ over expression lines, RNAi RNA interference lines, $h$ hours. Each value is the mean \pm standard deviation of three replicates. Significance differences were assessed by Duncan's test $\left(* P<0.05\right.$, $\left.{ }^{*} * P<0.01\right)$

CSSTS-RNAi lines and starch was accumulated. However, alteration of CSSTS expression did not seem to influence plant phenotype.

The consistent association of RFOs with intermediary cells suggests an integral role of RFOs synthesis for the phloem-loading mechanism (Ashlee and Turgeon 2007). The ultrastructural and molecular studies provide the experimental data to classify cucurbits as symplastic loaders (Mitchell and Madore 1992; Haritatos et al. 1996). In this study, the levels and distribution percentage 
of raffinose in the petioles of CSSTS-RNAi lines were significantly elevated; this may compensate partly for a lack of stachyose synthesis in RNA interference transgenic plants (Fig. 5). The results further confirm that the synthesis of RFOs in leaves is necessary for efficient phloem loading and transport, consistent with the polymer trapping model. This also revealed that in cucumber a symplastic phloem loading pathway dominates.

Many studies indicate that sucrose transporters (SUTs) are involved in apoplastic phloem loading (Lalonde et al. 2004; Braun and Slewinski 2009). Accordingly, downregulating of sucrose transporter VpSUT1 in the stachyosetransporting species Verbascum phoeniceum did not inhibit phloem loading (Zhang and Turgeon 2009). In this paper, we found up-regulation of CSSUT 1, 2 and 4 in CSSTSRNAi lines and their expressions were obviously higher than those of both the wild-type and CSSTS-OE lines, while there were no significant differences between CSSTS-OE and wild type plants (Fig. 5a). Although polymer trapping is the primary phloem loading strategy in cucurbits, the regulation of sucrose transporter expression levels in leaves and sucrose content in petioles of CSSTS-RNAi lines suggests that transgenic cucumber with interference expression of CSSTS probably contain the machinery for apoplastic phloem loading when the stachyose synthesis was blocked obviously. This result was similar to that of Gil et al. (2011), where melon plant CmSUT1 transcript expression in vascular bundles of minor veins increased significantly upon infection with cucumber mosaic virus (CMV), and was associated with elevated sucrose content in phloem sap collected from source-leaf petioles. Furthermore, AmSTS1, a stachyose synthase in the stachyose-translocating plant $A$. meridionalis, was expressed in the IC but not in the OCC of the same minor vein, while sucrose transporter AmSUT1 protein was present in OCC but not in the IC (Voitsekhovskaja et al. 2009). This indicates that both symplastic and apoplastic pathways can function simultaneously during phloem loading and these pathways are separated at the level of different sieve element-companion cell complexes combined in their phloem endings. However, the histochemical localization of cucumber sucrose transporters and their role in the phloem loading were elusive. Moreover, the "mixed" or "heterogeneous" loading mechanism of cucumber will need to be further confirmed with anatomical, physiological and molecular biology studies in the near future.

When plants are subjected to cold stress, soluble carbohydrates are differentially accumulated in vegetative tissues, and these cryoprotectant carbohydrates protect biological tissues from freezing damage (Imanishi et al. 1998; Zuther et al. 2004, 2012; Peters and Keller 2009). The RFO biosynthetic pathway is essentially an extension of the inositol metabolic pathway (Loewus and Murthy
2000; Sengupta et al. 2012). In plants, RFOs do not appear to have a direct functional relationship to stress amelioration under natural condition (Sengupta et al. 2015); the main RFO members, raffinose and stachyose, are stored in high concentrations and are not subject to rapid depletion under low temperature in order to increase cold tolerance of plants (Hinesley et al. 1992; Bachmann et al. 1994; Haab and Keller 2002; Tapernoux-Lüthi and Keller 2004).

The degree of low temperature damage to leaves in diverse plant types differ greatly. Cucumbers originate in the subtropics and belong to thermophilic crops, and they easily suffer damage under low temperature stress. Many experiments offer clarification for the roles of RFOs in stress protection, especially that of raffinose, which is ubiquitous in plants and has been implicated in tolerance to freezing in various species; examples include Vitis vinifera, Medicago sativa and even conifers (Castonguay et al. 1995; Strimbeck et al. 2007; Grant et al. 2009). Some studies have shown that RFOs may function to protect the thylakoid but not the plasma membrane during freezing in Arabidopsis (Iftime et al. 2011). Of course, there are many physiological and biochemical processes and reactions in the synthesis and transportation of stachyose. In this process, many substrates, intermediate products and enzymes are involved, and these different enzymes are regulated by their own genes. These genes, such as GolS (galactinol synthase), RS (raffinose synthetase) and STS, have their own specific roles and localizations within plant tissue; some exist as members of families genes and have diverged to perform specific but related functions such as the response to biotic and abiotic stresses. In our study, the level of membrane lipid peroxidation and cell membrane permeability, activities of SOD, CAT and POD protective enzymes and the content of osmotic adjusting materials in wild type or transgenic seedling increased gradually as suffering $6^{\circ} \mathrm{C}$ low temperature stress (Fig. 7). Moreover, after $72 \mathrm{~h}$ low temperature treatment, the leaves of CsSTS-RNAi lines were markedly wilted and sagged (Fig. 6e, f). This was likely related to the reduced expression of CsSTS along with reduced STS enzyme activity and stachyose content in CSSTS-RNAi seedlings relative to wild-type or especially CSSTS-OE lines (Fig. 6a-c). To be sure, CSSTS suppression significantly increased the peroxidation of membrane-lipid, decreased the stabilities of cell membrane system, and reduced the ability of resistance and adaption of cucumber plants to low temperature stress.

In summary, our study showed that CSSTS not only affects stachyose synthesis, phloem loading and the distribution of carbohydrates in the leaves, but also enhances the tolerance to low temperature stress.

Acknowledgements We thank Dr. Robert Turgeon (Cornell University) for critical reading of the article and the constructive comments. 
We also thank Dr. Xingfang Gu (Chinese Academy of Agricultural Sciences) for the gift of the "Xintaimici" cucumber seeds. This work was supported by the National Natural Science Foundation of China (Grant No. 31471876 to Z.Z.), the Ministry of Agriculture of China (Project No. 2013ZX08009), and the Beijing Fruit Vegetable Innovation Team (BAIC01-2017 to X.S.).

Author contributions $\mathrm{ZZ}$ and $\mathrm{XS}$ conceived and designed the experiments, JL, SM, XL and HL performed the experiments, JL, $\mathrm{SM}, \mathrm{XL}$ and $\mathrm{HL}$ analyzed the data, JL, XS and ZZ wrote the paper.

\section{Compliance with ethical standards}

Conflict of interest All authors declare that they have no conflict of interest.

Open Access This article is distributed under the terms of the Creative Commons Attribution 4.0 International License (http:// creativecommons.org/licenses/by/4.0/), which permits unrestricted use, distribution, and reproduction in any medium, provided you give appropriate credit to the original author(s) and the source, provide a link to the Creative Commons license, and indicate if changes were made.

\section{References}

Ashlee MC, Turgeon R (2007) Phloem loading in Verbascum phoeniceum L. depends on the synthesis of raffinose-family oligosaccharides. Proc Natl Acad Sci USA 104:19619-19624

Ayre BG (2011) Membrane-transport systems for sucrose in relation to whole-plant carbon partitioning. Mol Plant 4:377-394

Bachmann M, Matile P, Keller F (1994) Metabolism of the raffinose family oligosaccharides in leaves of Ajuga reptans L. (cold acclimation, translocation, and sink to source transition: discovery of chain elongation enzyme). Plant Physiol 105:1335-1345

Braun DM, Slewinski TL (2009) Genetic control of carbon partitioning in grasses: roles of sucrose transporters and tie-dyed loci in phloem loading. Plant Physiol 149:71-81

Braun DM, Wang L, Ruan YL (2013) Understanding and manipulating sucrose phloem loading, unloading, metabolism, and signalling to enhance crop yield and food security. J Exp Bot 65:1713-1735

Büchi R, Bachmann M, Keller F (1998) Carbohydrate metabolism in source leaves of sweet basil (Ocimum basilicum L.), a starchstoring and stachyose-translocating labiate. J Plant Physiol 153:308-315

Cakmak I, Marschner H (1992) Magnesium deficiency and high light intensity enhance activities of superoxide dismutase, ascorbate peroxidase and glutathione reductase in bean leaves. Plant Physiol 98:1222-1227

Castonguay Y, Nadeau P, Lechasseur P, Chouinard L (1995) Differential accumulation of carbohydrates in alfalfa cultivars of contrasting winterhardiness. Crop Sci 35:509-516

Chen L, Qu X, Hou B, Sosso D, Osorio S, Fernie A, Fernie AR, Frommer WB (2012) Sucrose efflux mediated by SWEET proteins as a key step for phloem transport. Science 335:207-211

Dagnall BH, Paulsen IT, Saier MH Jr (1995) The DAG family of glycosyl hydrolases combines two previously identified protein families. Biochem J 311:349-350

Downie B, Bewley JD (2001) Soluble sugar content of white spruce (Picea glauca) seeds during and after germination. Physiol Plant 110:1-12
Gamalei YV (2007) The role of mesophyll cell tonoplast in determining the route of phloem loading. Thirty years of the studies of phloem loading. Russ J Plant Physiol 54:1-9

Giannopolitis CN, Ries SK (1977) Superoxide dismutase. I. Occurrence in higher plant. Plant Physiol 59:309-314

Giaquinta RT (1983) Phloem loading of sucrose. Annu Rev Plant Physiol Mol Biol 34:347-387

Gil L, Yaron I, Shalitin D, Sauer N, Turgeon R, Wolf S (2011) Sucrose transporter plays a role in phloem loading in CMVinfected melon plants that are defined as symplastic loaders. Plant J 66:366-374

Gottwald JR, Krysan PJ, Young JC, Evert RF, Sussman MR (2000) Genetic evidence for the in planta role of phloem-specific plasma membrane sucrose transporters. Proc Natl Acad Sci USA 97:13979-13984

Grant TN, Dami IE, Ji T, Scurlock D, Streeter J (2009) Variation in leaf and bud soluble sugar concentration among Vitis genotypes grown under two temperature regimes. Can J Plant Sci 89:961-968

Haab CI, Keller F (2002) Purification and characterization of the raffinose oligosaccharide chain elongation enzyme, galactan: galactan galactosyltransferase (GGT), from Ajuga reptans leaves. Physiol Plant 114:361-371

Haritatos E, Keller F, Turgeon R (1996) Raffinose oligosaccharide concentrations measured in individual cell and tissue types in Cucumis melo L. leaves: implications for phloem loading. Planta 198:614-622

Hayes MA, Davies C, Dry IB (2007) Isolation, functional characterization, and expression analysis of grapevine (Vitis vinifera $\mathrm{L}$.) hexose transporters: differential roles in sink and source tissues. J Exp Bot 58:1985-1997

Hendrix JE (1968) Labeling pattern of translocated stachyose in squash. Plant Physiol 43:1631-1636

Hendrix JE (1982) Sugar translocation in two members of the cucurbitaceae. Plant Sci Lett 25:1-7

Henrissat B, Davies GJ (2000) Glycoside hydrolases and glycosyltransferases. Families, modules, and implications for genomics. Plant Physiol 124:1515-1519

Hinesley LE, Pharr DM, Snelling LK, Funderburk SR (1992) Foliar Raffinose and sucrose in four conifer species: relationship to seasonal temperature. J Am Soc Hortic Sci 117:852-855

Holthaus U, Schmitz K (1991a) Stachyose synthesis in mature leaves of Cucumis melo. Purification and characterization of stachyose synthase (EC 2.4.1.67). Planta 184:525-531

Holthaus U, Schmitz K (1991b) Distribution and immunolocalization of stachyose synthase in Cucumis melo L. Planta 185:479-486

Hu LP et al (2009) Changes in carbohydrate levels and their metabolic enzymes in leaves, phloem sap and mesocarp during cucumber (Cucumis sativus L.) fruit development. Sci Hortic 121:131-137

Huang H et al (2013) An efficient cucumber (Cucumis sativus L.) protoplast isolation and transient expression system. Sci Hortic 150:206-212

Iftime D, Hannah MA, Peterbauer T, Heyer AG (2011) Stachyose in the cytosol does not influence freezing tolerance of transgenic Arabidopsis expressing stachyose synthase from adzuki bean. Plant Sci 180:24-30

Imanishi HT, Suzuki T, Masuda K, Harada T (1998) Accumulation of raffinose and stachyose in shoot apices of Lonicera caerulea $\mathrm{L}$. during cold acclimation. Sci Hortic 72:255-263

Kötting O, Kossmann J, Zeeman SC, Lloyd JR (2010) Regulation of starch metabolism: the age of enlightenment? Curr Opin Plant Biol 13:320-328

Lalonde S, Wipf D, Frommer WB (2004) Transport mechanisms for organic forms of carbon and nitrogen between source and sink. Annu Rev Plant Biol 55:341-372 
Lemoine R et al (2013) Source-to-sink transport of sugar and regulation by environmental factors. Front Plant Sci 4:272

Liu W et al (2013) Protein kinase LTRPK1 influences cold adaptation and microtubule stability in rice. J Plant Growth Regul 32:483-490

Loescher WH, Everard JD (2000) Regulation of sugar alcohol biosynthesis. In: Leegood RC, Sharkey TD, von Caemmerer S (eds) Photosynthesis: physiology and metabolism. Kluwer Academic Publishers, Dordrecht, pp 275-299

Loewus FA, Murthy PPN (2000) Myo-Inositol metabolism in plants. Plant Sci 150:1-9

Mitchell DE, Madore MA (1992) Patterns of assimilate production and translocation in muskmelon (Cucumis melo L.): II. Low temperature effects. Plant Physiol 99:959-965

Noiraud N, Maurousset L, Lemoine R (2001) Transport of polyols in higher plants. Plant Physiol Biochem 39:717-728

Peterbauer T, Richter A (1998) Galactosylononitol and stachyose synthesis in seeds of adzuki bean. Purification and characterization of stachyose synthase. Plant Physiol 117:165-172

Peterbauer T, Mucha J, Popp M, Glössl J, Richter A (1999) Stachyose synthesis in seeds of adzuki bean (Vigna angularis): molecular cloning and functional expression of stachyose synthase. Plant $\mathbf{J}$ 20:509-518

Peterbauer T, Mucha J, Mach L, Richter A (2002) Chain elongation of raffinose in pea seeds. Isolation, characterization, and molecular cloning of multifunctional enzyme catalyzing the synthesis of stachyose and verbascose. J Biol Chem 277:194-200

Peters S, Keller F (2009) Frost tolerance in excised leaves of the common bugle (Ajuga reptans L.) correlates positively with the concentrations of raffinose family oligosaccharides (RFOs). Plant Cell Environ 32:1099-1107

Pharr DM, Huber SC, Sox HN (1985) Leaf carbohydrate status and enzymes of translocate synthesis in fruiting and vegetative plants of Cucumis sativus L. Plant Physiol 77:104-108

Reidel E, Rennie E, Amiard V, Cheng L, Turgeon R (2009) Phloem loading strategies in three plant species that transport sugar alcohols. Plant Physiol 149:1601-1608

Rennie EA, Turgeon R (2009) A comprehensive picture of phloem loading strategies. Proc Natl Acad Sci USA 106:14162-14167

Riesmeier JW, Willmitzer L, Frommer WB (1994) Evidence for an essential role of the sucrose transporter in phloem loading and assimilate partitioning. EMBO J 13:1-7

Saitou N, Nei M (1987) The neighbor-joining method: a new method for reconstructing phylogenetic trees. Mol Biol Evol 4:406-425

Saravitz DM, Pharr DM, Carter TE (1987) Galactinol synthase activity and soluble sugars in developing seeds of four soybean genotypes. Plant Physiol 83:185-189

Sengupta S, Mukherjee S, Parween S, Majumder AL (2012) Galactinol synthase across evolutionary diverse taxa: functional preference for higher plants? FEBS Lett 586:1488-1496

Sengupta S, Mukherjee S, Basak P, Majumder AL (2015) Significance of galactinol and raffinose family oligosaccharide synthesis in plants. Front Plant Sci 6:656

Shan DP et al (2007) Cotton ghdreb1 increases plant tolerance to low temperature and is negatively regulated by gibberellic acid. New Phytol 176:70-81
Slewinski TL, Braun DM (2010) Current perspectives on the regulation of whole-plant carbohydrate partitioning. Plant Sci 178:341-349

Slewinski TL, Zhang CK, Turgeon R (2013) Structural and functional heterogeneity in phloem loading and transport. Front Plant Sci $4: 244$

Strimbeck GR, Kjellsen TD, Schaberg PG, Murakami PF (2007) Cold in the common garden: comparative low-temperature tolerance of boreal and temperate conifer foliage. Trees 21:557-567

Sui X et al (2012) Molecular cloning, characteristics and low temperature response of raffinose synthase gene in Cucumis sativus L. J Plant Physiol 169:1883-1891

Tamura K, Peterson D, Peterson N, Stecher G, Nei M, Kumar S (2011) MEGA5 : molecular evolutionary genetics analysis using maximum likelihood, evolutionary distance, and maximum parsimony methods. Mol Biol Evol 28:2731-2739

Tanner W, Kandler O (1968) Myo-inositol, a cofactor in the biosynthesis of stachyose. Eur J Biochem 4:233-239

Tapernoux-Lüthi EM, Keller F (2004) Cloning, functional expression, and characterization of the raffinose oligosaccharide chain elongation enzyme, galactan: galactan galactosyltransferase, from common bugle leaves. Plant Physiol 134:1377-1387

Turgeon R (1996) Phloem loading and plasmodesmata. Trends Plant Sci 1:418-423

Turgeon R (2010) The role of phloem loading reconsidered. Plant Physiol 152:1817-1823

Turgeon R, Wolf S (2009) Phloem transport: cellular pathways and molecular trafficking. Annu Rev Plant Biol 60:207-221

Turgeon R, Webb JA, Evert RF (1975) Ultrastructure of minor veins in Cucurbita pepo leaves. Protoplasma 83:217-232

Unda F, Canam T, Preston L, Mansfield SD (2012) Isolation and characterization of galactinol synthases from hybrid poplar. J Exp Bot 63:2059-2069

Voitsekhovskaja OV et al (2009) Evidence for nctional heterogeneity of sieve element-companion cell complexes in minor vein phloem of Alonsoa meridionalis. J Exp Bot 60:1873-1883

Volk GM, Turgeon R, Beebe DU (1996) Secondary plasmodesmata formation in the minor-vein phloem of Cucumis melo L. and Cucurbita pepo L. Planta 199:425-432

Wang $\mathrm{H}$ et al (2014) Antisense suppression of cucumber (Cucumis sativus L.) sucrose synthase 3 (CsSUS3) reduces hypoxic stress tolerance. Plant Cell Environ 37:795-810

$\mathrm{Wu} \mathrm{J}$ et al (2012) Exogenous glucose preserves the quality of watermelon (Citrullus lanatus) plug seedlings for low-temperature storage. Sci Hortic 148:23-29

Zhang C, Turgeon R (2009) Downregulating the sucrose transporter VPSUT1 in Verbascum phoeniceum does not inhibit phloem loading. Proc Natl Acad Sci USA 106: 18849-18854

Zuther E, Buchel K, Hundertmark M, Stitt M, Hincha DK, Heyer AG (2004) The role of raffinose in the cold acclimation response of Arabidopsis thaliana. FEBS Lett 576:169-173

Zuther E, Schulz E, Childs LH, Hincha DK (2012) Clinal variation in the non-acclimated and cold-acclimated freezing tolerance of Arabidopsis thaliana accessions. Plant Cell Environ 35:1860-1878 